This document is the Accepted Manuscript version of a Published Work that appeared in final form in Chemistry of Materials, copyright (c) American Chemical Society after peer review and technical editing by the publisher. To access the final edited and published work see:

https://dx.doi.org/10.1021/acs.chemmater.8b00290. 


\title{
Triphenyl phosphite as phosphorous source for the scalable and cost-effective production of transition metal phosphides.
}

\author{
Junfeng Liu, ${ }^{1}$ Michaela Meyns, ${ }^{1}$ Ting Zhang, ${ }^{2}$ Jordi Arbiol,,${ }^{2,3}$ Andreu Cabot, ${ }^{1,3}$ Alexey Shavel ${ }^{1, *}$ \\ ${ }^{1}$ Catalonia Institute for Energy Research (IREC), Sant Adrià de Besòs, 08930 Barcelona, Spain. \\ ${ }^{2}$ Catalan Institute of Nanoscience and Nanotechnology (ICN2), CSIC and BIST, Campus UAB, Bellaterra, 08193 Barcelona, \\ Catalonia, Spain \\ ${ }^{3}$ ICREA, Pg. Lluis Companys 23, 08010 Barcelona, Spain
}

\begin{abstract}
Transition metal phosphides have great potential to optimize a number of functionalities in several energy conversion and storage applications, particularly when nanostructured or in nanoparticle form. However, the synthesis of transition metal phosphide nanoparticles and its scalability is often limited by the toxicity, air sensitivity and high cost of the reagents used. We present here a simple, scalable and cost-effective 'heating up' procedure to produce metal phosphides using inexpensive, lowtoxicity and air-stable triphenyl phosphite as source of phosphorous and chlorides as metal precursors. This procedure allows the synthesis of a variety of phosphide nanoparticles, including phosphides of $\mathrm{Ni}, \mathrm{Co}$ and $\mathrm{Cu}$. The use of carbonyl metal precursors further allowed the synthesis of $\mathrm{Fe}_{2} \mathrm{P}$ and $\mathrm{MoP}$ nanoparticles. The fact that minor modifications in the experimental parameters allowed producing nanoparticles with different compositions and even to tune their size and shape, shows the high potential and versatility of the triphenyl phosphite precursor and the presented method. We also detail here a methodology to displace organic ligands from the surface of phosphide nanoparticles which is a key step towards their application in energy conversion and storage systems.
\end{abstract}

\section{INTRODUTION}

Transition metal phosphides (TMP) are widely used in ion battery anodes ${ }^{1-4}$, as absorbers in photovoltaics ${ }^{5}$, supercapacitors $^{6}$ and as a catalysts in several processes including hydroprocessing $^{7-13}$, water-gas-shift reaction, ${ }^{14}$ and water splitting, ${ }^{15-}$ ${ }^{19}$ replacing costly and scarce noble metal catalysts.

In spite of their high potential, reports on catalytic properties of fairly well-shaped phosphide nanoparticles (NPs) are scarce, ${ }^{13,20-27}$ and generally carbon based nanostructures, decorated with phosphide nanoparticles have been tested as catalysts. Actually, very few routes for the synthesis of TMP nanoparticles with some control over their parameters exist. ${ }^{28,29}$ These previous works described the synthesis of phosphides of nickel ${ }^{22-25,30-34}$, cobalt $^{20,21,35}$, iron ${ }^{26,27,36,37}, \operatorname{tin}^{38}$, copper $^{39,40}$, and manganese ${ }^{41,42}$ as well as alloys of $\mathrm{CoMnP}^{43}, \mathrm{CoFeP}^{44}$, $\mathrm{Fe}_{\mathrm{x}} \mathrm{Ni}_{2-\mathrm{x}} \mathrm{P} 45$, 46 , and $\mathrm{Ni}_{2-\mathrm{x}} \mathrm{Co}_{\mathrm{x}} \mathrm{P}^{47}$.

Typically, TMP NPs are produced from the reaction of a metal precursor with substituted phosphines in the presence of aliphatic amines and acids. This strategy was initially applied to the synthesis of phosphides of manganese, iron, nickel, and cobalt using trioctylphosphine (TOP) as source of phosphorous. ${ }^{36,37,48}$ Later on, it was extended to a wider range of metal phosphides including $\mathrm{Pt}, \mathrm{Rh}, \mathrm{Pd}, \mathrm{Au}, \mathrm{Ag}, \mathrm{Ga}$, In, and $\mathrm{Zn} .{ }^{49}, 50$ Afterwards, a combination of TOP/TOPO was employed in the synthesis of $\mathrm{MnP}^{42}$ and $\mathrm{FeP}^{37}$ at higher reaction temperatures $>350^{\circ} \mathrm{C}$, although the role of TOPO in the NP formation is yet to be elucidated. Phosphines used as a source of phosphorous has been not limited only to TOP, but triphenylphosphine and tributylphosphine have been also used. ${ }^{30,} 31$ These and other achievements have been thoroughly reviewed. ${ }^{29}$

The exact mechanism of formation of phosphide NPs is not yet clear. Some of the publications suggest that metal NPs nucleate first and only in a second step they react with TOP (or other phosphines) to yield the corresponding phosphides. This mechanism was demonstrated in the one-pot synthesis of $\mathrm{Ni}_{2} \mathrm{P} .{ }^{50}$ In this direction, metal or even metal oxide NPs can be initially produced and in a second step reacted with a phosphorous source to produce the corresponding phosphides. ${ }^{20,21,51}$ Phosphidation of pre-formed metallic NPs frequently results into hollow nanostructures through the Kirkendall effect. ${ }^{52,53}$ This is for example the case for nickel phosphide ${ }^{23,25,31-34}$ and cobalt phosphide ${ }^{20,21}$ NPs. However, void formation can be avoided by keeping the $\mathrm{P} / \mathrm{Me}$ ratio sufficiently high $(>2.8) .{ }^{31}$,

${ }^{54}$ Importantly, the crystallinity of the phosphide NPs can be also tuned through the reaction temperature, producing amorphous NPs at low temperatures, ${ }^{30-32}$ and crystalline NPs at higher. In terms of NP geometry, no general rationale has been stablished, and NPs with different shapes, including spherical, cubic, rod-like or sea urchin-like, have been produced depending on the crystal structure of the phosphide and potentially of the metal or metal oxide initially formed and the synthetic conditions. As an example, sea urchin-like cobalt-iron phosphide NPs were obtained from the reaction of cubic oxide NPs with TOP as a source of phosphorous. ${ }^{55}$ 
Besides phosphines, other dangerous and toxic precursors such as $\mathrm{P}\left(\mathrm{SiMe}_{3}\right)_{3}{ }^{38,41,56,57}$, white phosphorous ${ }^{51,58,59}$ and even $\mathrm{PH}_{3}$ gas ${ }^{60,{ }_{61}}$ have been explored as phosphorous source for the preparation of phosphide NPs. On the other hand, commercially available metal precursors have been mostly limited to carbonyls, acetylacetonates and complexes with 1,5cyclooctadiene, with the exception of the use of $\mathrm{CuCl}$ to produce $\mathrm{Cu}_{3-\mathrm{x}} \mathrm{P}^{39}$ and $\mathrm{Cu}_{3} \mathrm{P}^{40,62}$. These are relatively costly precursors compared with chlorides. Even in the case of copper, the used $\mathrm{CuCl}$ is much more expensive than the more common $\mathrm{CuCl}_{2}$. Alternative single-source precursors have been also used to produce phosphide NPs, but these are even less costeffective than commercial options.

Overall, the reported procedures to produce metal phosphides generally possess a number of significant drawbacks which limits their potential for scale up and commercialization. In particular, TOP, the most commonly used source of phosphorus, is expensive, toxic and relatively unstable as it readily oxidizes at ambient conditions in air and thus needs proper storage and manipulation under inert atmosphere. Thus, we propose here the use of triphenyl phosphite (TPOP) as a convenient alternative to the sources of phosphorous currently used. TPOP has a very moderate cost and is stable in ambient conditions. To the best of our knowledge, in only one previous report the reactivity of TPOP was studied among that of several other candidates as a source of phosphorous for the synthesis of nickel phosphide. ${ }^{63}$ Surprisingly, in spite of the promising results obtained in this previous work, no follow up report has considered TPOP as phosphorous precursor. Apart from this, TPOP has been rarely used as a stabilizer in the synthesis of $\mathrm{Au}^{64}$ and $\mathrm{CuInS}_{2}{ }^{65,66} \mathrm{NPs}$. We report here the synthesis of various transition metal phosphides using this low cost and stable phosphorous precursor, a simple and scalable heating up procedure, ${ }^{67}$ and chlorides as low cost metal sources.

\section{EXPERIMENTAL SECTION}

Chemicals and solvents. Triphenyl phosphite (TPOP, 97\%) and tin (II) chloride $\left(\mathrm{SnCl}_{2}, 97 \%\right)$ were purchased from Alfa Aesar. Palladium (II) acetylacetonate (Pd(acac) $\left.)_{2}, 35 \% \mathrm{Pd}\right)$ and iron (III) acetylacetonate $\left(\mathrm{Fe}(\mathrm{acac})_{3}, 99 \%\right)$ were purchased from Acros. 1-Octadecene (ODE, 90\%), hexadecylamine (HDA, technical grade 90\%), nickel (II) chloride (98\%), nickel (II) chloride hexahydrate $\left(\mathrm{NiCl}_{2} \cdot 6 \mathrm{H}_{2} \mathrm{O}, 99.9 \%\right)$, cobalt (II) chloride $\left(\mathrm{CoCl}_{2}, 98 \%\right)$, copper(II) chloride $\left(\mathrm{CuCl}_{2}, 99 \%\right)$, iron pentacarbonyl $\left(\mathrm{Fe}(\mathrm{CO})_{5}, 99.999 \%\right)$, molybdenum hexacarbonyl $\left(\mathrm{Mo}(\mathrm{CO})_{6}, 98 \%\right)$, tungsten (VI) chloride $\left(\mathrm{WCl}_{6}, 99.9 \%\right)$, tin (II) acetylacetonate $\left(\mathrm{Sn}(\mathrm{acac})_{2}, 99.9 \%\right)$, manganese(II) acetylacetonate $\left(\mathrm{Mn}(\mathrm{acac})_{2}\right)$, manganese carbonyl $\left(\mathrm{Mn}_{2}(\mathrm{CO})_{10}\right.$, $98 \%$ ), manganese(II) chloride tetrahydrate $\left(\mathrm{MnCl}_{2} \cdot 4 \mathrm{H}_{2} \mathrm{O}\right.$, $99 \%$ ), tin (IV) chloride pentahydrate $\left(\mathrm{SnCl}_{4} \cdot 5 \mathrm{H}_{2} \mathrm{O}, 98 \%\right)$, tin oxalate $\left(\mathrm{SnC}_{2} \mathrm{O}_{4}, 98 \%\right)$, iron (II) chloride tetrahydrate $\left(\mathrm{FeCl}_{2} \cdot 4 \mathrm{H}_{2} \mathrm{O}\right.$, 99\%), iron (III) chloride hexahydrate $\left(\mathrm{FeCl}_{3} \cdot 6 \mathrm{H}_{2} \mathrm{O}, 99 \%\right)$ and indium (III) chloride $\left(\mathrm{InCl}_{3}, 98 \%\right)$ were purchased from Sigma Aldrich. Chloroform, isopropanol, ethanol and tetrahydrofuran (THF) were of analytical grade and obtained from various sources. All precursors and solvents were used without further purification.

In the following, base synthetic procedures are described. All used variations are thoroughly explained and discussed in the main text.
Phosphides of cobalt, nickel and copper. Standard synthesis (Me:HDA:TPOP = 1:10:10). Metal phosphide NPs were prepared by the reaction of metal chlorides with TPOP in the presence of HDA. In a typical synthesis, $0.5 \mathrm{mmol}$ of $\mathrm{MeCl}_{\mathrm{x}}$ (corresponding crystalohydrates were dissolved in a minimum amount of EtOH or THF prior addition) was mixed with $5.0 \mathrm{mmol}(1.207 \mathrm{~g})$ of HDA, $5.0 \mathrm{mmol}(1.551 \mathrm{~g})$ of TPOP and $10 \mathrm{~g}$ of ODE. The obtained mixture was heated under argon flow to $150{ }^{\circ} \mathrm{C}$ and maintained at this temperature for $\sim 1 \mathrm{~h}$ to dissolve the metal precursor and to ensure the removal of traces of low-boiling-point impurities, ethanol (or THF) and water. After purging, the solution was heated to boiling point (which is about $280-300{ }^{\circ} \mathrm{C}$, depending on the particular synthetic condition) and kept at that temperature during the desired period of time. Then, the mixture was allowed to cool naturally to $200{ }^{\circ} \mathrm{C}$, point at which the heating mantle was removed. Finally, NPs were thoroughly purified by multiple precipitation and redispersion steps, using 2propanol and chloroform.

Phosphides of iron and molybdenum. Standard synthesis. Unlike the other cases, carbonyls instead of chlorides were used to synthesize phosphides of iron and molybdenum. 0.5 mmols of $\mathrm{Fe}(\mathrm{CO})_{5}(98 \mathrm{mg} ; 66 \mu \mathrm{L})$ dissolved in $0.2 \mathrm{~mL}$ of ODE or $\mathrm{Mo}(\mathrm{CO})_{6}(132 \mathrm{mg})$ were added after the solvent cleaning step, just before the heating of the reaction mixture was started. $\mathrm{Fe}(\mathrm{CO})_{5}$ was injected by syringe, and $\mathrm{Mo}(\mathrm{CO})_{6}$ was quickly added into the opened flask under Ar flow. The rest of the synthetic procedure was as described above.

Tenfold synthesis (Me:HDA:TPOP = 1:5:5). To scale up the NP production a tenfold, the metal precursor amount was scaled-up by a factor of 10, HDA and TPOP by a factor of 5 and the amount of ODE was scaled-up only 2 times. All other synthetic conditions were the same as in the standard version of the synthesis.

Ligand exchange strategy: Organic ligands were displaced from the surface of $\mathrm{Co}_{2} \mathrm{P}$ NPs using $\mathrm{HPF}_{6}$. Note, that all the other tested compounds, such as $\mathrm{NaN}_{3}$ and even $\left[\mathrm{NBu}_{4}\right] \mathrm{PF}_{6}$, failed to displace original organic molecules. The $\mathrm{HPF}_{6}$ ligand exchange was performed by adding a drop of $\mathrm{HPF}_{6}$ (63 wt \% in water) and $10 \mathrm{ml}$ of formamide (or water) into a $10 \mathrm{ml}$ solution of $\mathrm{Co}_{2} \mathrm{P}$ NPs in chloroform. The mixture was vigorously stirred and let stand until phase separation was observed. NPs moved from the chloroform to the formamide (or water) phase. The final formamide or water solution containing the NPs was washed several times with chloroform to drag all the remaining organic ligands surrounding the NPs. NPs were finally precipitated using acetonitrile and redispersed in N,Ndimethylformamide. Finally, the solution was cleaned by precipitation with acetone and redispersion in DMF.

Instrumentation. The morphological, chemical and structural characterization of the NPs was carried out by transmission electron microscopy (TEM) using a ZEISS LIBRA 120, operating at $120 \mathrm{KV}$ and JEOL 1011 operating at $100 \mathrm{kV}$. Carbon-coated TEM grids from Ted-Pella were used as substrates. High resolution transmission electron microscopy (HRTEM) images were obtained using a FEI Tecnai F20 fieldemission gun microscope operated at $200 \mathrm{keV}$ with an embedded Gatan image filter for electron energy loss spectroscopy (EELS) analyses. Images were analyzed by means of Gatan Digital Micrograph software. Powder X-ray diffraction (XRD) 
patterns were obtained with Ni-filtered ( $2 \mu \mathrm{m}$ thickness) $\mathrm{Cu}$ $\mathrm{K} \alpha_{1}(\lambda=1.5406 \AA)$ radiation in a reflection geometry on a Bruker-AXS D8-Discover diffractometer operating at $40 \mathrm{kV}$ and $40 \mathrm{~mA}$. For the SEM-EDX measurements, phosphide NPs were drop-casted on the SEM specimen stubs, covered by the silicon wafer and naturally dried.

\section{RESULTS AND DISCUSSION}

Figures 1-5 display representative TEM images of the $10 \pm 1$ $\mathrm{nm}$ quasi-spherical $\mathrm{Ni}_{2} \mathrm{P}$ (figure 1), $5 \pm 1 \mathrm{~nm} \times 22 \pm 5 \mathrm{~nm}$ rodshaped $\mathrm{Fe}_{2} \mathrm{P}$ (figure 2), $6.9 \pm 0.8 \mathrm{~nm}$ x $33 \pm 9 \mathrm{~nm}$ rod-shaped $\mathrm{Co}_{2} \mathrm{P}$ (figure 3), $4.5 \pm 1 \mathrm{~nm} \times 17 \pm 1 \mathrm{~nm}$ disk-shaped $\mathrm{Cu}_{3} \mathrm{P}$ (figure 4) and the $<5 \mathrm{~nm}$ quasi-spherical MoP (figure 5) NPs prepared following the above detailed procedure. In the case of $\mathrm{Co}_{2} \mathrm{P}$, both quasi-spherical and rod-like particles could be produced, depending on the synthetic conditions, as further discussed below.

$\mathrm{Ni}_{2} \mathrm{P}, \mathrm{Co}_{2} \mathrm{P}$ and $\mathrm{Cu}_{3} \mathrm{P}$ NPs were obtained upon heating of the metal chlorides in a mixture of TPOP as a phosphorous source and possible stabilizer, HDA as stabilizer and ODE as a solvent. The formation of phosphide NPs started when the temperature was raised above ca. $250{ }^{\circ} \mathrm{C}$ as noted by a gradual darkening of the reaction mixture. The reaction yield, measured from the collected NPs after purification, was above $80 \%$ in all cases.

The syntheses of iron and molybdenum phosphides included few minor differences from the other phosphide NPs. Iron chlorides, either $\mathrm{FeCl}_{3}$ or $\mathrm{FeCl}_{2}$, could not be used as metal precursor due to the exceptional stability of the formed iron complexes. Even prolonged heating did not provide iron phosphide using these precursors. Higher temperatures could make the reaction possible, but temperature was limited by TPOP by-products. $\mathrm{MoCl}_{5}$-based complexes are much less stable than those obtained from iron chlorides, but they neither resulted in any identifiable molybdenum phosphide phase upon reaction with TPOP (Figure S1). Subsequently, iron and molybdenum phosphides were produced using the corresponding carbonyls as metal precursors. It is important to mention that both $\mathrm{Fe}(\mathrm{CO})_{5}$ and $\mathrm{Mo}(\mathrm{CO})_{6}$ are low boiling point compounds and they must be introduced to the synthesis just before the final heating stage (after the solvent cleaning stage) to prevent their loss during solvent cleaning.

Generally, amorphous NPs were initially formed and prolonged reaction times were required to properly crystalize them. For all the phosphides reported here, except for molybdenum phosphide, crystalline NPs were obtained in solution at temperatures below $300{ }^{\circ} \mathrm{C}$. In the case of $\mathrm{MoP}$, a postpreparative thermal annealing of the dried NPs at a higher temperature, $800{ }^{\circ} \mathrm{C}$, was needed to form the proper crystalline structure. Figure 5e displays the XRD patterns of the MoP NPs before and after a thermal process at $800{ }^{\circ} \mathrm{C}$ for $2 \mathrm{~h}$.

The stable hexagonal crystallographic structures were obtained for all the metal phosphides produced and regardless the experimental conditions and synthesis details. Only in the case of nickel, the tetragonal $\mathrm{Ni}_{12} \mathrm{P}_{5}$ phase (space group $\mathrm{I} / \mathrm{m}$ ) was also obtained during the initial stage of the synthesis, as further discussed below. In particular, $\mathrm{Ni}_{2} \mathrm{P}$ NPs displayed a hexagonal crystal phase, space group (SG) $\mathrm{P}_{321}$, with $\mathrm{a}=\mathrm{b}=0.588 \mathrm{~nm}, \mathrm{c}=0.336 \mathrm{~nm}$ (Figure $1 \mathrm{~b}$ ). Similarly rod-shaped
$\mathrm{Fe}_{2} \mathrm{P}$ NPs had a hexagonal crystal phase, SG P-62m, with $\mathrm{a}=\mathrm{b}=0.5865 \mathrm{~nm}, \mathrm{c}=0.3456 \mathrm{~nm}$ (Figure $2 \mathrm{~b}$ ). $\mathrm{Co}_{2} \mathrm{P}$ nanorods also displayed a hexagonal phase, SG P-62m, with $\mathrm{a}=5.7420 \AA$, $\mathrm{b}=$ $5.7420 \AA, c=3.4570 \AA$ (Figure $3 b$ ). $\mathrm{Cu}_{3} \mathrm{P}$ NPs showed the hexagonal phase, SG P63cm, with $\mathrm{a}=6.9593 \AA, \mathrm{b}=6.9593 \AA$, $\mathrm{c}=7.1430 \AA$ (Figure 4b).

Figures 1c-5c display EELS chemical composition maps of the different phosphides (see additional data in the supporting information). A uniform distribution of phosphorus and metal atoms in each of the analyzed NPs was observed. However, phosphorous- and especially oxygen-rich surfaces were also detected. Surface $\mathrm{O}$ and $\mathrm{P}$ atoms most probably reflected the presence of an oxygen-containing stabilizer, probably TPOP, in a shell surrounding each NP. It is also possible that a partial surface oxidation of the NPs took place during post-synthetic washing step, where all procedures were carried out under ambient conditions. In addition, a thin oxide shell could be formed or grown during sample preparation for TEM characterization, as we used oxygen-Ar plasma cleaning to remove organic contamination.

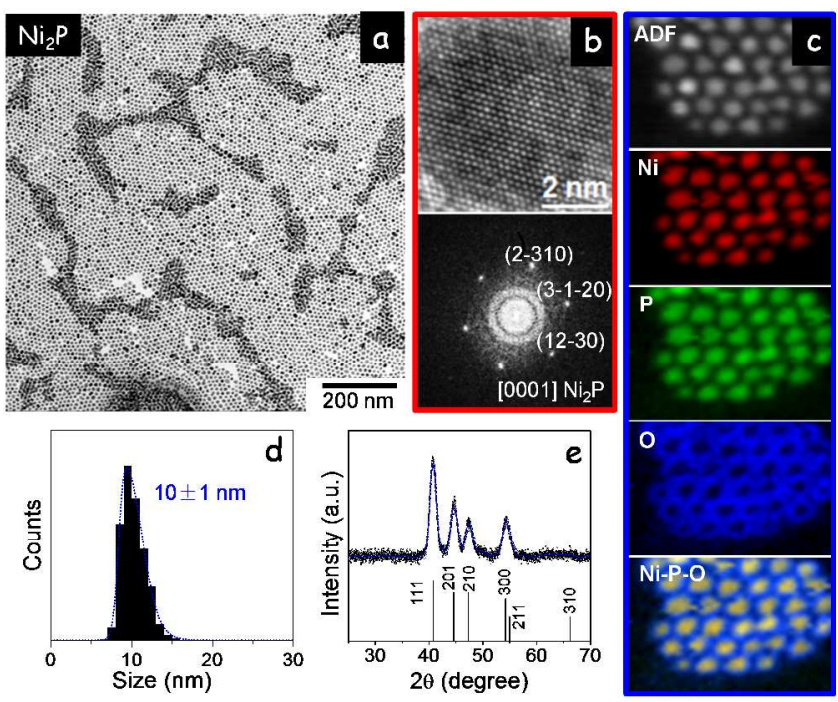

Figure 1. TEM micrograph (a); HRTEM micrograph and corresponding power spectrum (b); ADF-STEM and EELS compositional maps (c); size distribution histogram (d); and XRD pattern of $\mathrm{Ni}_{2} \mathrm{P}$ NPs (e). The reference JCPDS pattern of $\mathrm{Ni}_{2} \mathrm{P}(00-003-$ 0953) was also included in the XRD graph. The lattice fringe distances from the HRTEM micrograph were measured as 0.185 $\mathrm{nm}, 0.187 \mathrm{~nm}$ and $0.187 \mathrm{~nm}$, at 59.41 and $120.39^{\circ}$ which is consistent with the hexagonal $\mathrm{Ni}_{2} \mathrm{P}$ phase, visualized along its [0001] zone axis. 

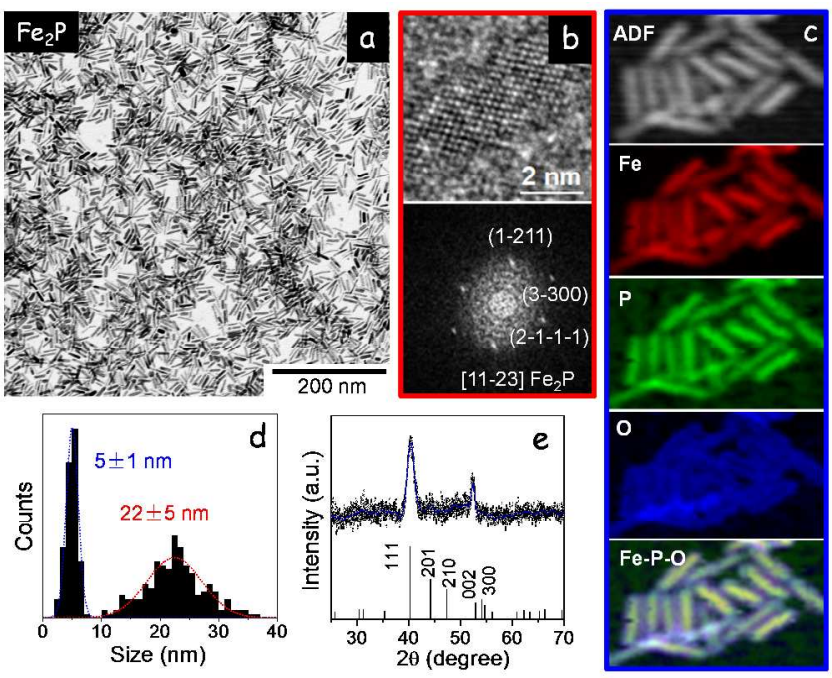

Figure 2. TEM micrograph (a); HRTEM micrograph and corresponding power spectrum (b); ADF-STEM and EELS compositional maps (c); nanorod length and thickness distribution histograms, (d); and XRD pattern of $\mathrm{Fe}_{2} \mathrm{P}$ NPs (e). The reference JCPDS pattern of $\mathrm{Fe}_{2} \mathrm{P}$ (01-076-089) was also included in the XRD graph. The lattice fringe distances from the HRTEM micrograph were measured as $0.218 \mathrm{~nm}, 0.168 \mathrm{~nm}$ and $0.214 \mathrm{~nm}$, at $50^{\circ}$ and $100^{\circ}$, respectively, which is consistent with the hexagonal $\mathrm{Fe}_{2} \mathrm{P}$ phase, visualized along its [11-23] zone axis.
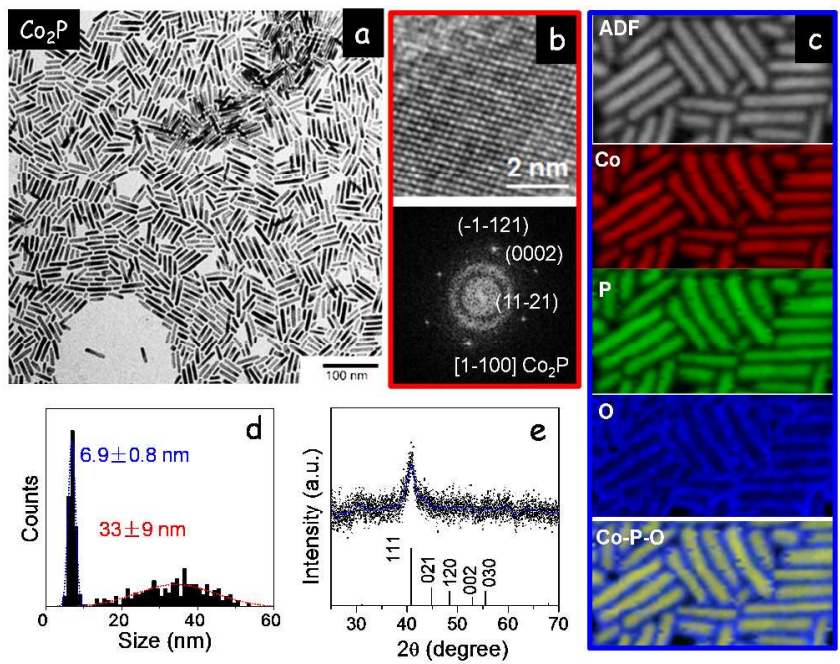

Figure 3. TEM micrograph (a); HRTEM micrograph and corresponding power spectrum (b); ADF-STEM and EELS compositional maps (c); nanorod length and thickness distribution histograms (d); and XRD pattern of $\mathrm{Co}_{2} \mathrm{P}$ NPs (e). The reference JCPDS pattern of $\mathrm{Co}_{2} \mathrm{P}$ (00-054-0413) was also included in the XRD graph. From the HRTEM micrograph, the $\mathrm{Co}_{2} \mathrm{P}$ lattice fringe distances were measured to be $0.218 \mathrm{~nm}, 0.172 \mathrm{~nm}, 0.218$ $\mathrm{nm}$ and $0.220 \mathrm{~nm}$, at $50.78^{\circ}, 101.44^{\circ}$, and $78.71^{\circ}$ which is consistent with the hexagonal $\mathrm{Co}_{2} \mathrm{P}$ phases, visualized along its [1$100]$ zone axis.
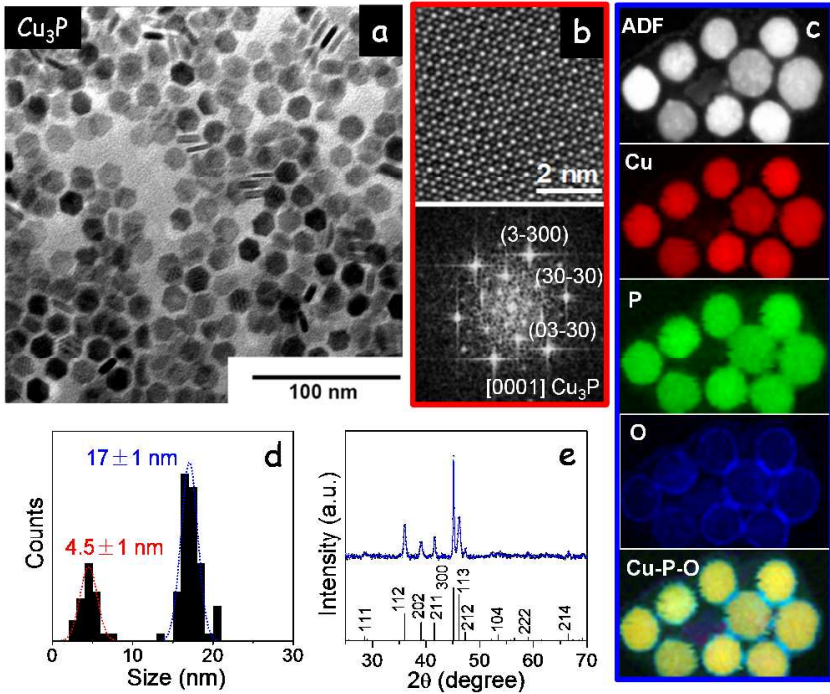

Figure 4. TEM micrograph (a); HRTEM micrograph and corresponding power spectrum (b); ADF-STEM and EELS compositional maps (c); disk diameter and thickness distribution histograms (d); and XRD pattern of $\mathrm{Cu}_{3} \mathrm{P}$ NPs (e). The reference JCPDS pattern of $\mathrm{Cu}_{3} \mathrm{P}$ (01-071-2261) was also included in the $\mathrm{XRD}$ graph. From the HRTEM micrograph, the $\mathrm{Cu}_{3} \mathrm{P}$ lattice fringe distances were measured to be $0.198 \mathrm{~nm}, 0.197 \mathrm{~nm}$ and $0.197 \mathrm{~nm}$, at $60.39^{\circ}, 119.72^{\circ}$ which is consistent with the hexagonal phase, visualized along its [0001] zone axis.

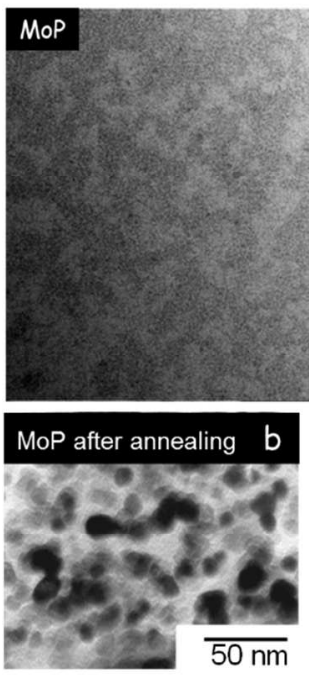

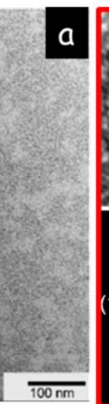
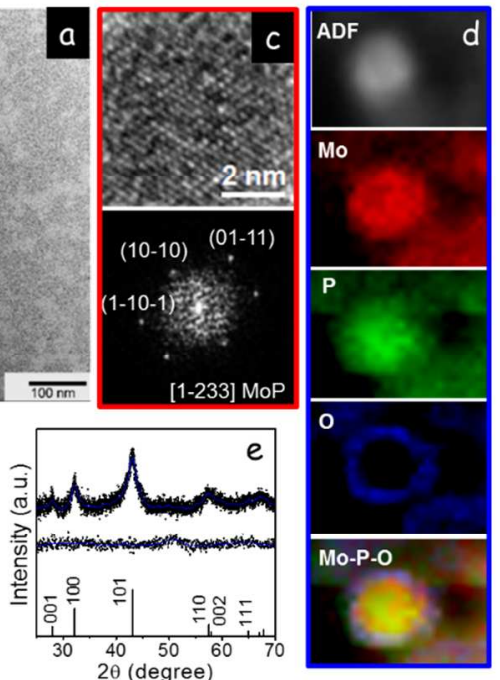

Figure 5. a) TEM micrograph of as-produced MoP NPs. b) TEM micrograph of MoP NPs after thermal treatment at $800{ }^{\circ} \mathrm{C}$ for $2 \mathrm{~h}$. c) HRTEM micrograph and corresponding power spectrum of annealed MoP NPs. d) ADF-STEM and EELS compositional maps of annealed NPs. e) XRD pattern of annealed MoP NPs. The reference JCPDS pattern of MoP (00-024-0771) was also included in the XRD graph. 
Importantly, the proposed synthetic strategy could be easily scaled up. Figure S2 shows $\mathrm{Co}_{2} \mathrm{P}$ NPs produced when scaling up the synthesis procedure a tenfold. Even larger amounts of TMP NPs per batch might be prepared simply by using large reaction vessels and through further concentration increase, as it has been demonstrated for a wide range of NPs. ${ }^{68,69}$

The case of Ni was particularly helpful to provide additional information about the NP formation path. Hexagonal $\mathrm{Ni}_{2} \mathrm{P} \mathrm{NPs}$ where obtained from the reaction of $\mathrm{NiCl}_{2}$ with TPOP in the presence of HDA and at a temperature close to $300{ }^{\circ} \mathrm{C}$ as detailed above. However, when the reaction temperature was limited to below $250{ }^{\circ} \mathrm{C}$, close to amorphous Ni-P NPs were obtained (figure 6e). The exact $\mathrm{Ni}: \mathrm{P}$ stoichiometry of these NPs could not be determined since large amounts of unreacted TPOP were systematically left on the analyzed samples, possibly in part bound at the NP surface. Besides, when the amount of HDA was reduced by half (Me:HDA:TPOP ratio $1: 5: 10)$ and the reaction was quenched immediately before the solvent boiling point was reached, $\mathrm{Ni}_{12} \mathrm{P}_{5}$ NPs with a tetragonal phase, SG $\mathrm{I} 4 / \mathrm{m}$, were obtained (figure 6). From these observations, we conclude that the reaction of $\mathrm{NiCl}_{2}$ with TPOP in the presence of HDA initially results in amorphous Ni or Ni-P NPs. Subsequently, we hypothesize that phosphorous ions are being introduced in the NPs, which may initially crystallize in the tetragonal Ni-rich phase $\mathrm{Ni}_{12} \mathrm{P}_{5}$ and later, when a higher amount of $\mathrm{P}$ has been introduced, on the hexagonal $\mathrm{Ni}_{2} \mathrm{P}$. This hypothesis remains to be fully confirmed with additional in situ experiments.
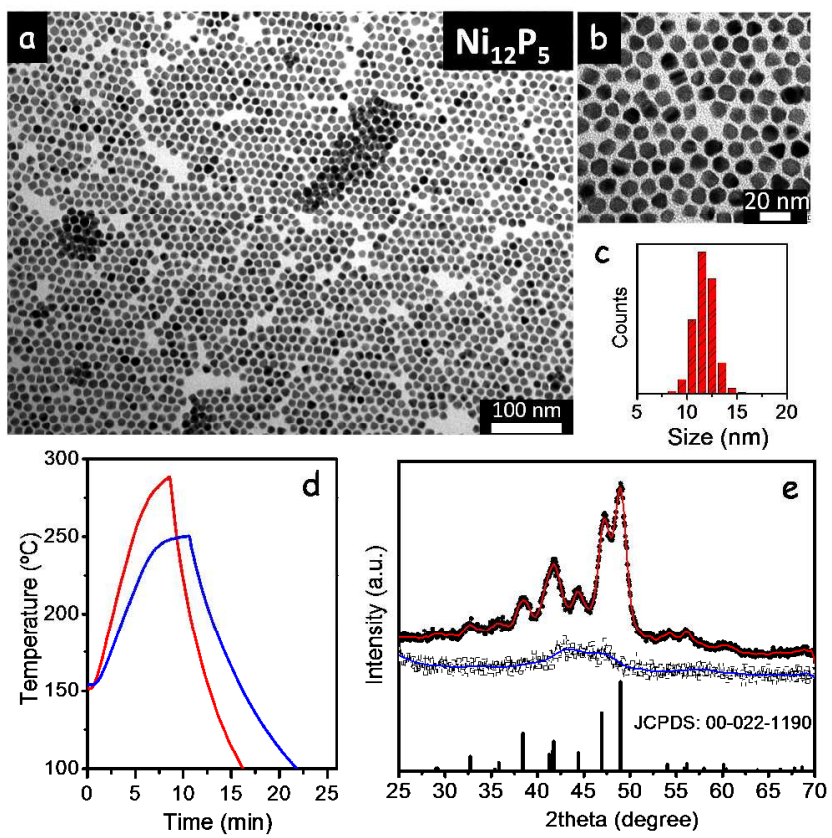

Figure 6. a), b) Representative TEM micrographs of $\mathrm{Ni}_{12} \mathrm{P}_{5} \mathrm{NPs}$ prepared using a Me:HDA:TPOP ratio 1:5:10 and by quenching the reaction immediately before the solvent boiling point was reached. c) Size distribution histogram. d) Temperature profiles (after solvent cleaning) of the synthesis procedure at high, i.e. just below the boiling point, (red) and low, up to $250{ }^{\circ} \mathrm{C}$, (blue) temperature. e) XRD patterns of the materials prepared at high (red) and low (blue) temperatures.
The variation of the reaction conditions substantially influenced the size, shape and crystallinity of the phosphide NPs produced. As an example, the evolution of the crystallinity of the $\mathrm{Ni}_{2} \mathrm{P}$ NPs depended on the TPOP concentration. Figure 7 shows TEM micrographs of the $\mathrm{Ni}_{2} \mathrm{P}$ NPs produced with different amounts of TPOP. While the size of $\mathrm{Ni}_{2} \mathrm{P}$ NPs increased with the concentration of TPOP, their crystallinity, in terms of the size obtained from XRD patterns through the Scherrer equation, did not change significantly (figure 7e). Similarly, the reaction time did not have a significant influence on the material crystallinity once formed the $\mathrm{Ni}_{2} \mathrm{P}$ phase (figure $\mathrm{S9}$ ). It is worth to mention that the geometrical size, obtained from TEM images, of the $\mathrm{Ni}_{2} \mathrm{P}$ was systematically larger than the size obtained from the fitting of the XRD pattern (figure 7e).
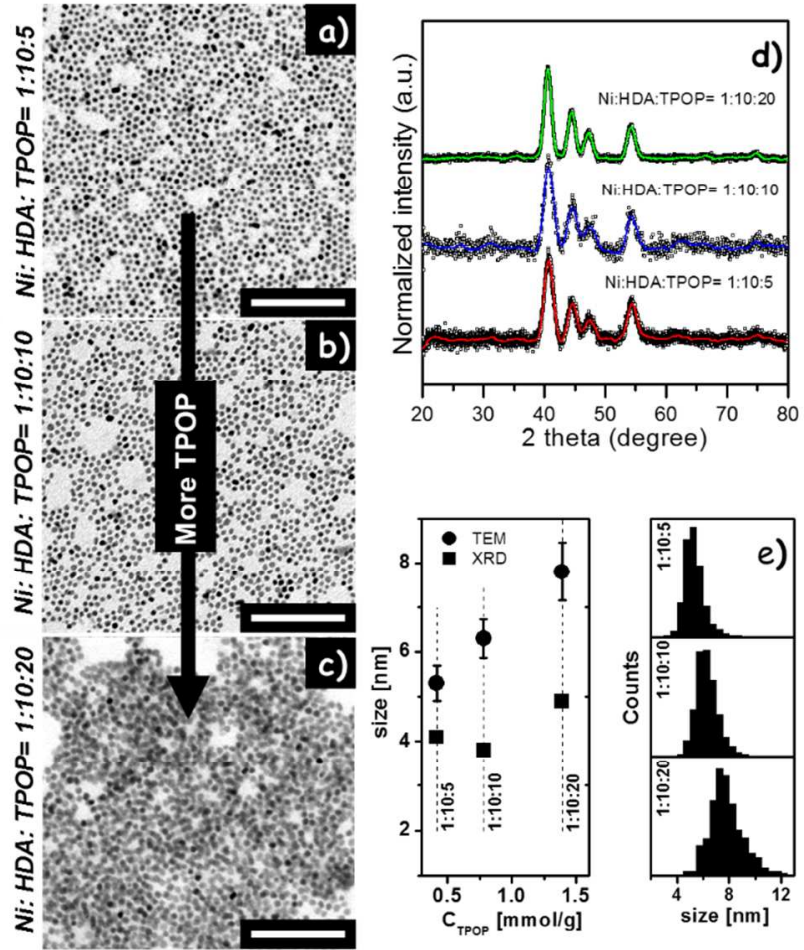

Figure 7. TEM micrographs (a-c) and XRD patterns (d) showing the dependence of the $\mathrm{Ni}_{2} \mathrm{P}$ NPs with the concentration of TPOP. e) Size evolutions extracted from TEM images and XRD patterns. Numbers indicate Ni:HDA:TPOP ratios during the synthesis. All scale bars correspond to $100 \mathrm{~nm}$.

Figure 8 shows the $\mathrm{Co}_{2} \mathrm{P}$ and $\mathrm{Fe}_{2} \mathrm{P}$ NPs produced with different concentrations of precursors in the synthetic mixture. While the rod-like NP geometry was preserved, the monodispersity and overall NP quality significantly decreased when increasing the Me/HDA ratio. Reducing the amount of HDA, $\mathrm{Co}_{2} \mathrm{P}$ and $\mathrm{Fe}_{2} \mathrm{P}$ NPs lost the accurate cylindrical shape, becoming more irregular and with less defined edges. Generally, a Me:HDA:TPOP $=1: 10: 10$ ratio resulted in highest quality NPs. However, more detailed and systematic experiments need to be done to fully understand how the NPs' morphology depends on the experimental conditions and to fully optimize the synthetic protocol, especially when scaling up and maximizing the reactant concentrations. 
Besides TPOP, FTIR analysis indicated the presence of HDA at the NPs surface (figure 9). The presence of these organics may strongly reduce the NP performance in all applications involving charger transport or transfer from/to the NPs, including catalysis. Surface ligands could not be displaced using previously reported procedures with molecules such as $\left[\mathrm{NBu}_{4}\right] \mathrm{PF}_{6}, \mathrm{NaN}_{3}, \mathrm{NaSCN}$, etc. However, organic-free phosphide NPs could be obtained by displacing organic ligands with $\mathrm{HPF}_{6}$ (figure 9). The detailed ligand displacement procedure and TEM images of $\mathrm{Co}_{2} \mathrm{P}$ NPs before and after ligand displacement can be found in the supporting information (figure S10).

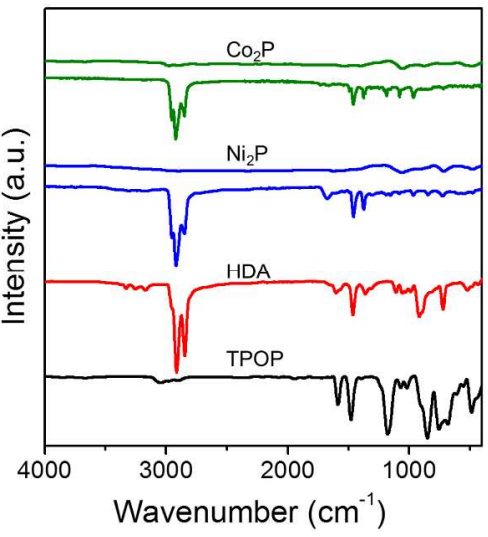

Figure 9. FTIR spectra of TPOP, HDA, as-produced $\mathrm{Ni}_{2} \mathrm{P}$ and $\mathrm{Co}_{2} \mathrm{P}$ (below) and $\mathrm{Ni}_{2} \mathrm{P}$ and $\mathrm{Co}_{2} \mathrm{P}$ after ligand removal (above).

\section{POSSIBLE REACTION MECHANISM}

We observed that the shape of $\mathrm{Co}_{2} \mathrm{P}$ NPs significantly changed with the argon flow rate (figure 10). Quasi-spherical $\mathrm{Co}_{2} \mathrm{P}$ NPs (figure 10a) were obtained when using strong argon flows during the reaction, but rod-shaped NPs (figure 10b) were prepared at low (about $30 \mathrm{~mL} \mathrm{~min}^{-1}$ ) flows of inert gas. The key to understand this shape variation with the argon flow might be in the in situ formation of ammonium salts, which would be fully expelled from the reaction mixture only at high argon flows. Such ammonium salts are well-known shapegoverning agents. For example, $\mathrm{Pd}_{2} \mathrm{Sn}$ nanorods were prepared using $\mathrm{HDA} \cdot \mathrm{HCl}^{70}$ Iron oxide octahedrons were synthesized with the help of trioctylammonium bromide. ${ }^{71}$ In the same direction, we hypothesize that we produced $\mathrm{Co}_{2} \mathrm{P}$ nanorods or quasi-spherical NPs depending on the presence or absence of $\mathrm{HDA} \cdot \mathrm{HCl}$ during the synthesis, which was related with the capacity of the used argon flow to displace this in situ formed compound. This shape control mechanism does not apply to the case of $\mathrm{Fe}_{2} \mathrm{P}$ nanorods, where a carbonyl instead of a chloride was used as metal precursor. Actually, $\mathrm{Fe}_{2} \mathrm{P}$ nanorods were obtained regardless of the argon flow rate.

The particular mechanism of in situ formation of $\mathrm{HCl}$ in the reaction mixture was revealed in previous studies demonstrating the reaction of TPOP with nickel ${ }^{72}$ and copper ${ }^{73}$ chlorides. TPOP reduced the chlorides during the complex formation and resulted in the formation of $\mathrm{HCl}$. Such formed $\mathrm{HCl}$, would instantly react with present amines to produce the corresponding ammonium salts. In our case, complexes might be formed during the initial degassing/cleaning step (argon bubbling at $150{ }^{\circ} \mathrm{C}$ ) and the overall reaction might be represented by the following scheme:

$$
\begin{aligned}
2 \mathrm{MeCl}_{\mathrm{x}} & +5 \mathrm{x}(\mathrm{RO})_{3} \mathrm{P}+2 \mathrm{xHDA}+\mathrm{xH}_{2} \mathrm{O} \rightarrow \\
& \rightarrow 2 \mathrm{Me}\left[\mathrm{P}(\mathrm{OR})_{3}\right]_{2 \mathrm{x}}+2 \mathrm{xHDA} \cdot \mathrm{HCl}+\mathrm{x}(\mathrm{RO})_{3} \mathrm{P}=\mathrm{O}
\end{aligned}
$$

TPOP plays a double role here, as a ligand in the formed metal complexes and as reducing agent, which underlines the importance of adding this reagent in excess. The exact compositions of the formed metal complexes depend on the nature of the metal and on the particular conditions of the synthesis (e.g. amount of ODE, HDA, TPOP, temperature, etc.) and cannot be revealed at the present moment. The complexes of interest coexist with excesses of TPOP and HDA, which most proba- 
bly participate in the reaction as ligands, and cannot be easily separated and studied. Details of how $\mathrm{HDA} \cdot \mathrm{HCl}$ influences the shape of phosphide NPs would strongly depend on the surface chemistry in every particular case and it is going to be matter of our future work.

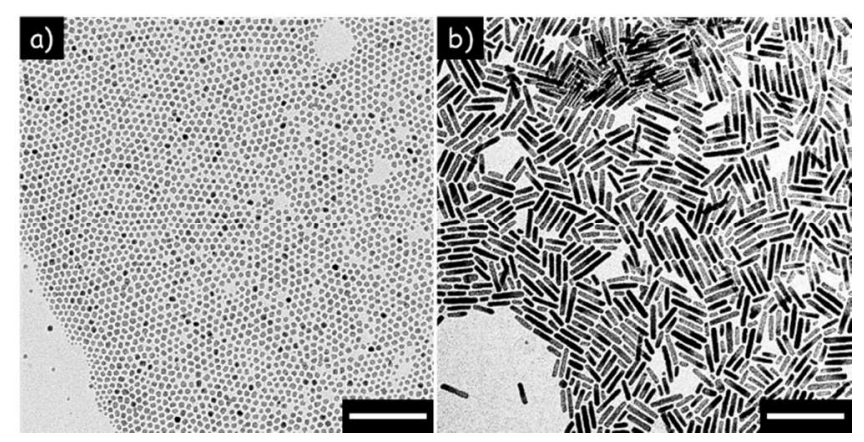

Figure 10. TEM images of the $\mathrm{Co}_{2} \mathrm{P}$ NPs prepared with high (left) and low (right) argon flows. All scale bars are $100 \mathrm{~nm}$.

\section{NEGATIVE RESULTS}

Even though phosphide NPs of $\mathrm{Ni}, \mathrm{Co}, \mathrm{Cu}, \mathrm{Fe}$ and $\mathrm{Mo}$ could be produced using TPOP as phosphorous source, phosphides of other tested metals, such as In, Sn, Mn, Pd and W, could not be produced in the same conditions. In some cases, e.g. In and Sn, no reaction was detected at all. The color of the solution did not change even during prolonged heat treatment and no product could be precipitated from the reaction solution. Similarly, only an unidentified, white-yellow flaky product was obtained from the reaction of TPOP with $\mathrm{MnCl}_{2}$ under the same conditions (see XRD pattern in the supporting information). The replacement of chlorides by other metal precursors was not successful. In this direction, for $\mathrm{Mn}$ and $\mathrm{Sn}$, $\mathrm{MnCl}_{2}, \mathrm{Mn}(\mathrm{acac})_{2}, \mathrm{Mn}_{2}(\mathrm{CO})_{10}, \mathrm{SnCl}_{2}, \mathrm{SnCl}_{4} \cdot 5 \mathrm{H}_{2} \mathrm{O}, \mathrm{Sn}(\text { acac })_{2}$, and $\mathrm{SnC}_{2} \mathrm{O}_{4}$ were tested without success. On the other hand, metallic $\mathrm{W}$ and $\mathrm{Pd}$ NPs were obtained using $\mathrm{WCl}_{6}$ and $\operatorname{Pd}(\mathrm{acac})_{2}$ as metal sources.

\section{CONCLUSION}

In summary, we detailed a straightforward, cost-effective and up-scalable procedure to produce phosphide NPs. The keys to this synthesis protocol were the use of cheap, stable, easy-to-handle precursors in a 'heating up' synthetic process. Particularly, TPOP was used as an inexpensive and air-stable source of phosphorous, and mainly metal chlorides, as a similarly convenient source of metals. Stable and low-toxicity precursors not only significantly simplified the synthetic procedure but also rendered unnecessary the use of glove-box as well as many other usual precautions. Additional simplification of the synthetic procedure was achieved through the introduction of the 'heating up' methodology - the simplest and easiest to scale up, compared to the classical injection-based protocols. Both amorphous and crystalline NPs could be prepared through careful reaction temperature/time adjustment. Additionally the shape and size of the NPs could be controlled for particular materials by modifying the protocols for each individual compound. Moreover, we demonstrated the scalability of the detailed protocol and described a procedure to displace the organic ligands from the surface of the as- synthesized materials. With these possibilities at hand it will be possible to further explore the many interesting properties and applications of TMP.

\section{ASSOCIATED CONTENT}

Supporting Information. Additional HRTEM micrograph and the EELS chemical composition maps obtained from the STEM micrograph for the phospspides of the nickel, iron, cobalt and copper; TEM images and size distribution histograms (thickness and length) of the $\mathrm{Co}_{2} \mathrm{P}$ nanoparticles obtained from a tenfold scaled synthesis; Safety and toxicity issues of phosphorous precursors; Ligand exchange procedure; TEM images of $\mathrm{Co}_{2} \mathrm{P}$ nanoparticles before and after ligand exchange; XRD pattern of the unidentified material prepared with $\mathrm{MoCl}_{5}$; XRD patterns of the $\mathrm{Ni}_{2} \mathrm{P}$ NPs, prepared during 5 and 60 minutes; TEM image, EDXSEM spectrum and XRD pattern of the unidentified material prepared with $\mathrm{WCl}_{6}$.

\section{AUTHOR INFORMATION}

\section{Corresponding Author}

\section{*al.shavel@gmail.com}

\section{Author Contributions}

The manuscript was written through contributions of all authors. / All authors have given approval to the final version of the manuscript. /

\section{Funding Sources}

European Regional Development Funds and the Spanish Ministerio de Economía y Competitividad through the projects SEHTOP (ENE2016-77798-C4-3-R), ANAPHASE (ENE201785087-C3-3-R) and grant no. SEV-2013-0295.

\section{ACKNOWLEDGMENT}

This work was supported by the European Regional Development Funds and the Spanish Ministerio de Economía y Competitividad through the project SEHTOP (ENE2016-77798-C4-3-R). JL thanks the China Scholarship Council for scholarship support. MM thanks the Spanish MINECO for her Juan de la Cierva scholarship. TZ and JA acknowledge funding from Generalitat de Catalunya 2017 SGR 327 and the Spanish MINECO coordinated project ANAPHASE (ENE2017-85087-C3-3-R). ICN2 acknowledges support from the Severo Ochoa Programme (MINECO, Grant no. SEV-2013-0295) and is funded by the CERCA Programme / Generalitat de Catalunya. Part of the present work has been performed in the framework of Universitat Autònoma de Barcelona Materials Science $\mathrm{PhD}$ program. TZ has received funding from the CSC-UAB PhD scholarship program.

\section{ABBREVIATIONS}

ODE, 1-octadene; THF, tetrahydrofuran; NPs, nanoparticles; TMP, transition metal phosphides; TOP, trioctylphosphine; TOPO, trioctylphosphine oxide; TPOP, triphenyl phosphite; HDA, hexadecylamine.

\section{REFERENCES}

1. Liu, J.; Xu, X.; Hu, R.; Liu, J.; Ouyang, L.; Zhu, M., SelfSupported CoP Nanorod Arrays Grafted on Stainless Steel as an 
Advanced Integrated Anode for Stable and Long-Life Li-Ion Batteries. Chem.-Eur. J. 2017, 23, 5198-5204.

2. Lou, P.; Cui, Z.; Jia, Z.; Sun, J.; Tan, Y.; Guo, X., Monodispersed Carbon-Coated Cubic $\mathrm{NiP}_{2}$ Nanoparticles Anchored on Carbon Nanotubes as Ultra-Long-Life Anodes for Reversible Lithium Storage. ACS Nano 2017, 11, 3705-3715.

3. Poli, F.; Wong, A.; Kshetrimayum, J. S.; Monconduit, L.; Letellier, M., In Situ NMR Insights into the Electrochemical Reaction of $\mathrm{Cu}_{3} \mathrm{P}$ Electrodes in Lithium Batteries. Chem. Mater. 2016, 28, 1787-1793.

4. Feng, Y.; Zhang, H.; Mu, Y.; Li, W.; Sun, J.; Wu, K.; Wang, Y., Monodisperse Sandwich-Like Coupled Quasi-Graphene Sheets Encapsulating $\mathrm{Ni}_{2} \mathrm{P}$ Nanoparticles for Enhanced Lithium-Ion Batteries. Chem.-Eur. J. 2015, 21, 9229-9235.

5. Scanlon, D. O.; Walsh, A., Bandgap Engineering of $\mathrm{ZnSnP}_{2}$ for High-Efficiency Solar Cells. Appl. Phys. Lett. 2012, 100, 251911.

6. Kong, M.; Wang, Z.; Wang, W.; Ma, M.; Liu, D.; Hao, S.; Kong, R.; Du, G.; Asiri, A. M.; Yao, Y.; others, NiCoP Nanoarray: A Superior Pseudocapacitor Electrode with High Areal Capacitance. Chem.-Eur. J. 2017, 23, 4435-4441.

7. Oyama, S. T., Novel Catalysts for Advanced Hydroprocessing: Transition Metal Phosphides. J. Catal. 2003, 216, 343-352.

8. Stinner, C.; Prins, R.; Weber, T., Binary and Ternary TransitionMetal Phosphides as HDN Catalysts. J. Catal. 2001, 202, 187-194.

9. Li, K.; Wang, R.; Chen, J., Hydrodeoxygenation of Anisole over Silica-Supported $\mathrm{Ni}_{2} \mathrm{P}, \mathrm{MoP}$, and NiMoP Catalysts. Energy \& Fuels 2011, 25, 854-863.

10. Habas, S. E.; Baddour, F. G.; Ruddy, D. A.; Nash, C. P.; Wang, J.; Pan, M.; Hensley, J. E.; Schaidle, J. A., A Facile Molecular Precursor Route to Metal Phosphide Nanoparticles and their Evaluation as Hydrodeoxygenation Catalysts. Chem. Mater. 2015, 27, 7580-7592.

11. Liu, P.; Rodriguez, J., A.; Asakura, T.; Gomes, J. o.; Nakamura, K., Desulfurization reactions on $\mathrm{Ni}_{2} \mathrm{P}(001)$ and $\alpha-\mathrm{Mo}_{2} \mathrm{C}$ (001) surfaces: Complex role of $\mathrm{P}$ and $\mathrm{C}$ sites. J. Phys. Chem. B 2005, $109,4575-4583$.

12. Sawhill, S. J.; Phillips, D. C.; Bussell, M. E., Thiophene Hydrodesulfurization over Supported Nickel Phosphide Catalysts. $J$. Catal. 2003, 215, 208-219.

13. Senevirathne, K.; Burns, A. W.; Bussell, M. E.; Brock, S. L., Synthesis and characterization of discrete nickel phosphide nanoparticles: effect of surface ligation chemistry on catalytic hydrodesulfurization of thiophene. Adv. Funct. Mater. 2007, 17, 3933-3939.

14. Liu, P.; Rodriguez, J., A.; Takahashi, Y.; Nakamura, K., WaterGas-Shift Reaction on a $\mathrm{Ni}_{2} \mathrm{P}(001)$ Catalyst: Formation of Oxyphosphides and Highly Active Reaction Sites. J. Catal. 2009, 262, 294-303.

15. Shi, Y.; Zhang, B., Recent Advances in Transition Metal Phosphide Nanomaterials: Synthesis and Applications in Hydrogen Evolution Reaction. Chem. Soc. Rev. 2016, 45, 1529-1541.

16. Zeng, M.; Li, Y., Recent Advances in Heterogeneous Electrocatalysts for the Hydrogen Evolution Reaction. J. Mater. Chem. A 2015, 3, 14942-14962.

17. Xiao, P.; Chen, W.; Wang, X., A Review of Phosphide-Based Materials for Electrocatalytic Hydrogen Evolution. Adv. Energy Mater. 2015, 5

18. Feng, L.; Vrubel, H.; Bensimon, M.; Hu, X., Easily-Prepared Dinickel Phosphide $\left(\mathrm{Ni}_{2} \mathrm{P}\right)$ Nanoparticles as an Efficient and Robust Electrocatalyst for Hydrogen Evolution. Phys. Chem. Chem. Phys. 2014, 16, 5917-5921.

19. Wang, X.; Kolen'ko, Y. V.; Bao, X.-Q.; Kovnir, K.; Liu, L., One-Step Synthesis of Self-Supported Nickel Phosphide Nanosheet Array Cathodes for Efficient Electrocatalytic Hydrogen Generation. Angew. Chem., Int. Ed. 2015, 54, 8188-8192.

20. Popczun, E. J.; Read, C. G.; Roske, C. W.; Lewis, N. S.; Schaak, R. E., Highly active electrocatalysis of the hydrogen evolution reaction by cobalt phosphide nanoparticles. Angew. Chem. 2014, 126, 5531-5534

21. Callejas, J. F.; Read, C. G.; Popczun, E. J.; McEnaney, J. M.; Schaak, R. E., Nanostructured $\mathrm{Co}_{2} \mathrm{P}$ electrocatalyst for the hydrogen evolution reaction and direct comparison with morphologically equivalent CoP. Chem. Mater. 2015, 27, 3769-3774.

22. Cao, S.; Chen, Y.; Wang, C.-J.; He, P.; Fu, W.-F., Highly efficient photocatalytic hydrogen evolution by nickel phosphide nanoparticles from aqueous solution. Chem. Commun. 2014, 50, 10427-10429.

23. Pan, Y.; Liu, Y.; Zhao, J.; Yang, K.; Liang, J.; Liu, D.; Hu, W.; Liu, D.; Liu, Y.; Liu, C., Monodispersed Nickel Phosphide Nanocrystals with Different Phases: Synthesis, Characterization and Electrocatalytic Properties for Hydrogen Evolution. J. Mater. Chem. A 2015, 3, 1656-1665.

24. Han, A.; Chen, H.; Sun, Z.; Xu, J.; Du, P., High catalytic activity for water oxidation based on nanostructured nickel phosphide precursors. Chem. Commun. 2015, 51, 11626-11629.

25. Popczun, E. J.; McKone, J. R.; Read, C. G.; Biacchi, A. J.; Wiltrout, A. M.; Lewis, N. S.; Schaak, R. E., Nanostructured Nickel Phosphide as an Electrocatalyst for the Hydrogen Evolution Reaction. J. Am. Chem. Soc. 2013, 135, 9267-9270.

26. Callejas, J. F.; McEnaney, J. M.; Read, C. G.; Crompton, J. C.; Biacchi, A. J.; Popczun, E. J.; Gordon, T. R.; Lewis, N. S.; Schaak, R. E., Electrocatalytic and Photocatalytic Hydrogen Production From Acidic and Neutral-pH Aqueous Solutions Using Iron Phosphide Nanoparticles. ACS Nano 2014, 8, 11101-11107.

27. Chung, D. Y.; Jun, S. W.; Yoon, G.; Kim, H.; Yoo, J. M.; Lee, K.-S.; Kim, T.; Shin, H.; Sinha, A. K.; Kwon, S. G.; others, Largescale Synthesis of Carbon Shell-coated FeP Nanoparticles for Robust Hydrogen Evolution Reaction Electrocatalyst. J. Am. Chem. Soc. 2017, 139, 6669-6674.

28. Brock, S. L.; Perera, S. C.; Stamm, K. L., Chemical Routes for Production of Transition-Metal Phosphides on the Nanoscale: Implications for Advanced Magnetic and Catalytic Materials. Chem.Eur. J. 2004, 10, 3364-3371.

29. Carenco, S.; Portehault, D.; Boissiere, C.; Mezailles, N.; Sanchez, C., Nanoscaled Metal Borides and Phosphides: Recent Developments and Perspectives. Chem. Rev. 2013, 113, 7981-8065.

30. Mandel, K.; Dillon, F.; Koos, A. A.; Aslam, Z.; Jurkschat, K.; Cullen, F.; Crossley, A.; Bishop, H.; Moh, K.; Cavelius, C.; others, Facile, Fast, and Inexpensive Synthesis of Monodisperse Amorphous Nickel-Phosphide Nanoparticles of Predefined Size. Chem. Commun. 2011, 47, 4108-4110.

31. Wang, J.; Johnston-Peck, A. C.; Tracy, J. B., Nickel Phosphide Nanoparticles with Hollow, Solid, and Amorphous Structures. Chem. Mater. 2009, 21, 4462-4467.

32. Moreau, L. M.; Ha, D.-H.; Zhang, H.; Hovden, R.; Muller, D. A.; Robinson, R. D., Defining Crystalline/Amorphous Phases of Nanoparticles Through X-ray Absorption Spectroscopy and X-ray Diffraction: the Case of Nickel Phosphide. Chem. Mater. 2013, 25, 2394-2403.

33. Chiang, R. K.; Chiang, R. T., Formation of Hollow $\mathrm{Ni}_{2} \mathrm{P}$ Nanoparticles Based on the Nanoscale Kirkendall Effect. Inorg Chem. 2007, 46, 369-371

34. Muthuswamy, E.; Savithra, G. H. L.; Brock, S. L., Synthetic Levers Enabling Independent Control of Phase, Size, and Morphology in Nickel Phosphide Nanoparticles. ACS Nano 2011, 5, 2402-2411.

35. Zhang, S.-Y.; Ye, E.; Liu, S.; Lim, S. H.; Tee, S. Y.; Dong, Z.; Han, M.-Y., Temperature and Chemical Bonding-Directed SelfAssembly of Cobalt Phosphide Nanowires in Reaction Solutions into Vertical and Horizontal Alignments. Adv. Mater. 2012, 24, 43694375.

36. Park, J.; Koo, B.; Hwang, Y.; Bae, C.; An, K.; Park, J.-G.; Park, H. M.; Hyeon, T., Novel Synthesis of Magnetic $\mathrm{Fe}_{2} \mathrm{P}$ Nanorods from Thermal Decomposition of Continuously Delivered Precursors Using a Syringe Pump. Angew. Chem., Int. Ed. 2004, 43, 2282-2285. 
37. Qian, C.; Kim, F.; Ma, L.; Tsui, F.; Yang, P.; Liu, J., SolutionPhase Synthesis of Single-Crystalline Iron Phosphide Nanorods/Nanowires. J. Amer. Chem. Soc. 2004, 126, 1195-1198.

38. Tallapally, V.; Esteves, R. J. A.; Nahar, L.; Arachchige, I. U., Multivariate Synthesis of Tin Phosphide Nanoparticles: Temperature, Time, and Ligand Control of Size, Shape, and Crystal Structure. Chem. Mater. 2016, 28, 5406-5414.

39. De Trizio, L.; Gaspari, R.; Bertoni, G.; Kriegel, I.; Moretti, L.; Scotognella, F.; Maserati, L.; Zhang, Y.; Messina, G. C.; Prato, M.; others, $\mathrm{Cu}_{3-\mathrm{x}} \mathrm{P}$ Nanocrystals as a Material Platform for Near-Infrared Plasmonics and Cation Exchange Reactions. Chem. Mater. 2015, 27, $1120-1128$

40. De Trizio, L.; Figuerola, A.; Manna, L.; Genovese, A.; George, C.; Brescia, R.; Saghi, Z.; Simonutti, R.; Huis, M. V.; Falqui, A., Size-Tunable, Hexagonal Plate-like $\mathrm{Cu}_{3} \mathrm{P}$ and Janus-like $\mathrm{Cu}-\mathrm{Cu}_{3} \mathrm{P}$ Nanocrystals. ACS Nano 2012, 6, 32-41.

41. Perera, S. C.; Tsoi, G.; Wenger, L. E.; Brock, S. L., Synthesis of MnP Nanocrystals by Treatment of Metal Carbonyl Complexes with Phosphines: A New, Versatile Route to Nanoscale Transition Metal Phosphides. J. Amer. Chem. Soc. 2003, 125, 13960-13961.

42. Gregg, K. A.; Perera, S. C.; Lawes, G.; Shinozaki, S.; Brock, S. L., Controlled synthesis of MnP nanorods: Effect of shape anisotropy on magnetization. Chem. Mater. 2006, 18, 879-886.

43. Li, D.; Baydoun, H.; Verani, C. a., udio N.; Brock, S. L., Efficient Water Oxidation Using CoMnP Nanoparticles. J. Amer. Chem. Soc. 2016, 138, 4006-4009.

44. Mendoza-Garcia, A.; Zhu, H.; Yu, Y.; Li, Q.; Zhou, L.; Su, D.; Kramer, M. J.; Sun, S., Controlled Anisotropic Growth of Co-Fe-P from Co-Fe-O Nanoparticles. Angew. Chem., Int. Ed. 2015, 54, 96429645 .

45. Hitihami-Mudiyanselage, A.; Arachchige, M. P.; Seda, T.; Lawes, G.; Brock, S. L., Synthesis and Characterization of Discrete $\mathrm{Fe}_{\mathrm{x}} \mathrm{Ni}_{2-\mathrm{x}} \mathrm{P}$ Nanocrystals $(0<\mathrm{x}<2)$ : Compositional Effects on Magnetic Properties. Chem. Mater. 2015, 27, 6592-6600.

46. Yoon, K. Y.; Jang, Y.; Park, J.; Hwang, Y.; Koo, B.; Park, J.G.; Hyeon, T., Synthesis of Uniform-Sized Bimetallic Iron-Nickel Phosphide Nanorods. J. Solid State Chem. 2008, 181, 1609-1613.

47. Liyanage, D. R.; Danforth, S. J.; Liu, Y.; Bussell, M. E.; Brock, S. L., Simultaneous Control of Composition, Size, and Morphology in Discrete $\mathrm{Ni}_{2-\mathrm{x}} \mathrm{Co}_{\mathrm{X}} \mathrm{P}$ Nanoparticles. Chem. Mater. 2015, 27, 4349-4357.

48. Park, J.; Koo, B.; Yoon, K. Y.; Hwang, Y.; Kang, M.; Park, J.G.; Hyeon, T., Generalized synthesis of metal phosphide nanorods via thermal decomposition of continuously delivered metal-phosphine complexes using a syringe pump. J. Am. Chem. Soc. 2005, 127, 84338440 .

49. Henkes, A. E.; Schaak, R. E., Trioctylphosphine: a general phosphorus source for the low-temperature conversion of metals into metal phosphides. Chem. Mater. 2007, 19, 4234-4242.

50. Henkes, A. E.; Vasquez, Y.; Schaak, R. E., Converting metals into phosphides: a general strategy for the synthesis of metal phosphide nanocrystals. J. Am. Chem. Soc. 2007, 129, 1896-1897.

51. Carenco, S.; Hu, Y.; Florea, I.; Ersen, O.; Boissière, C.; Mèzailles, N.; Sanchez, C., Metal-dependent interplay between crystallization and phosphorus diffusion during the synthesis of metal phosphide nanoparticles. Chem. Mater. 2012, 24, 4134-4145.

52. Yin, Y.; Rioux, R. M.; Erdonmez, C. K.; Hughes, S.; Somorjai, G. A.; Alivisatos, A. P., Formation of hollow nanocrystals through the nanoscale Kirkendall effect. Science 2004, 304, 711-714.

53. Yin, Y. D.; Erdonmez, C. K.; Cabot, A.; Hughes, S.; Alivisatos, A. P., Colloidal synthesis of hollow cobalt sulfide nanocrystals. $A d v$. Funct. Mater. 2006, 16, 1389-1399.

54. Cabot, A.; Ibáñez, M.; Guardia, P.; Alivisatos, A. P., Reaction regimes on the synthesis of hollow particles by the Kirkendall effect. $J$ Am Chem Soc 2009, 131, 11326-11328.

55. Mendoza-Garcia, A.; Su, D.; Sun, S., Sea urchin-like cobalt-iron phosphide as an active catalyst for oxygen evolution reaction. Nanoscale 2016, 8, 3244-3247.
56. Perera, S. C.; Fodor, P. S.; Tsoi, G. M.; Wenger, L. E.; Brock, S. L., Application of De-silylation Strategies to the Preparation of Transition Metal Pnictide Nanocrystals: The Case of FeP. Chem. Mater. 2003, 15, 4034-4038.

57. Liu, Z.; Mu, H.; Xiao, S.; Wang, R.; Wang, Z.; Wang, W.; Wang, Y.; Zhu, X.; Lu, K.; Zhang, H.; others, Pulsed Lasers Employing Solution-Processed Plasmonic $\mathrm{Cu}_{3-\mathrm{x}} \mathrm{P}$ Colloidal Nanocrystals. Adv. Mater. 2016, 28, 3535-3542.

58. Carenco, S.; Resa, I.; Le Goff, X.; Le Floch, P.; Mézailles, N., White phosphorus as single source of "P" in the synthesis of nickel phosphide. Chem. Commun. 2008, 2568-2570.

59. Carenco, S.; Le Goff, X. F.; Shi, J.; Roiban, L.; Ersen, O.; Boissière, C.; Sanchez, C.; Mézailles, N., Magnetic Core- Shell Nanoparticles from Nanoscale-Induced Phase Segregation. Chem. Mater. 2011, 23, 2270-2277.

60. Son, C. Y.; Kwak, I. H.; Lim, Y. R.; Park, J., FeP and $\mathrm{FeP}_{2}$ nanowires for efficient electrocatalytic hydrogen evolution reaction. Chem. Commun. 2016, 52, 2819-2822.

61. Dutta, A.; Dutta, S. K.; Mehetor, S. K.; Mondal, I.; Pal, U.; Pradhan, N., Oriented Attachments and Formation of Ring-on-Disk Heterostructure $\mathrm{Au}-\mathrm{Cu}_{3} \mathrm{P}$ Photocatalysts. Chem. Mater. 2016, 28, 1872-1878.

62. Manna, G.; Bose, R.; Pradhan, N., Semiconducting and plasmonic copper phosphide platelets. Angew. Chem. 2013, 52, 67626766.

63. Andaraarachchi, H. P.; Thompson, M. J.; White, M. A.; Fan, H.-J.; Vela, J., Phase-Programmed Nanofabrication: Effect of Organophosphite Precursor Reactivity on the Evolution of Nickel and Nickel Phosphide Nanocrystals. Chem. Mater. 2015, 27, 8021-8031.

64. Weare, W. W.; Reed, S. M.; Warner, M. G.; Hutchison, J. E., Improved synthesis of small $(\mathrm{d}$ core $\approx 1.5 \mathrm{~nm})$ phosphine-stabilized gold nanoparticles. J. Am. Chem. Soc. 2000, 122, 12890-12891.

65. Czekelius, C.; Hilgendorff, M.; Spanhel, L.; Bedja, I.; Lerch, M.; Müller, G. Bloeck, U.; Su, D.-S.; Giersig, M., A Simple Colloidal Route to Nanocrystalline $\mathrm{ZnO} / \mathrm{CuInS}_{2}$ Bilayers. Adv. Mater. 1999, 11, 643-646.

66. Arici, E.; Sariciftci, N. S.; Meissner, D., Hybrid Solar Cells Based on Nanoparticles of $\mathrm{CuInS}_{2}$ in Organic Matrices. Adv. Funct. Mater. 2003, 13, 165-171.

67. van Embden, J.; Chesman, A. S. R.; Jasieniak, J. J., The HeatUp Synthesis of Colloidal Nanocrystals. Chem. Mater. 2015, 27, 2246-2285.

68. Williamson, C. B.; Nevers, D. R.; Hanrath, T.; Robinson, R. D., Prodigious Effects of Concentration Intensification on Nanoparticle Synthesis: A High-Quality, Scalable Approach. J. Amer. Chem. Soc. 2015, 137, 15843-15851.

69. Shavel, A.; Ibáñez, M.; Luo, Z.; De Roo, J.; Carrete, A.; Dimitrievska, M.; Genc, A.; Meyns, M.; Pérez-Rodríguez, A.; Kovalenko, M. V.; others, Scalable heating-up synthesis of monodisperse $\mathrm{Cu}_{2} \mathrm{ZnSnS}_{4}$ nanocrystals. Chem. Mater. 2016, 28, 720 726.

70. Luo, Z.; Ibáñez, M.; Antolín, A. M.; Genç, A.; Shavel, A.; Contreras, S.; Medina, F.; Arbiol, J.; Cabot, A., Size and aspect ratio control of $\mathrm{Pd}_{2} \mathrm{Sn}$ nanorods and their water denitration properties. Langmuir 2015, 31, 3952-3957.

71. Shavel, A.; Rodríguez-González, B.; Pacifico, J.; Spasova, M.; Farle, M.; Liz-Marzán, L. M., Shape Control in Iron Oxide Nanocrystal Synthesis, Induced by Trioctylammonium Ions. Chem. Mater. 2009, 21, 1326-1332.

72. Vinal, R. S.; Reynolds, L. T., The Reduction of Nickel (II) Halides by Trialkyl Phosphites. Inorg. Chem. 1964, 3, 1062-1063.

73. Cook, B. W.; Miller, R. G. J.; Todd, P. F., A New Route to Olefin Complexes of Copper (I) Compounds. J. Organomet. Chem. 1969, 19, 421-430. 
Table of Contents artwork:

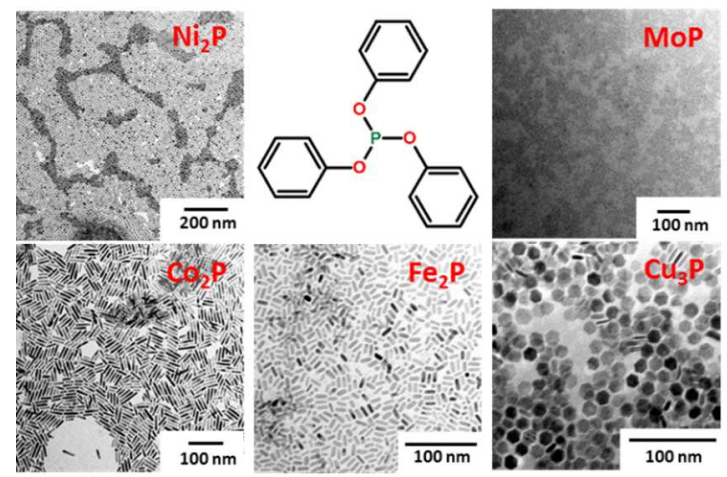

